\title{
SIGNIFICANCE OF LOCAL F18 FDG PET/CT IMAGING IN LUNG CANCER
}

şadiye tuzcu ${ }^{1}$, bekir taşdemir ${ }^{1}$, ibrahim iblioğlu ${ }^{1}$, ihsan kaplan ${ }^{2}$, ali uyar ${ }^{1}$, fatih güzel ${ }^{1}$, and yunus güzel ${ }^{3}$

${ }^{1}$ Dicle Universitesi

${ }^{2}$ Diyarbakir Gazi Yasargil Training and Research Hospital

${ }^{3}$ Diyarbakır Gazi Yaşargil Eğitim ve Araştırma Hastanesi

August 4, 2021

\begin{abstract}
Background: The evaluation of solitary lung nodules via FDG PET/CT has high sensitivity for nodules larger than 8 mm and is utilized to exclude lung cancer. Aim: This study aimed to retrospectively explore whether the lesions in patients who underwent F18 fluorodeoxyglucose-positron emission tomography/computed tomography imaging with the staging of the solitary pulmonary nodule and lung mass were within the local imaging area. It also investigated whether a relationship existed between the size of the lung lesion and extrathoracic spread. Materials and Method: Three hundred eight patients histopathologically diagnosed lung cancer were included in this study. All patients lung lesions were measured and patients were classified as four groups according to the size of the lung lesion. In all groups, the F18 FDG PET/CT examination was used to detect liver, adrenal, bone and supraclavicular lymph node metastasis, besides extrathoracic metastasis. Results: Liver, bone and extrathoracic metastasis of group-1 was statistically lower than group-2 $(\mathrm{P}<0.001, \mathrm{p}<0.01$ and $\mathrm{P}=0.03$, respectively). Liver, extrathoracic, adrenal and bone metastasis of group-3 was statistically lower than the group-4 ( $\mathrm{P}<0.001$, $\mathrm{P}=0.01$, and $\mathrm{P}=0.04, \mathrm{p}<0.01$ respectively). Extrathoracic extension was observed in only one patient in the group-3. In addition liver, adrenal, and bone metastases were not observed in any group-3 patients. Conclusions: PET/CT may be a more appropriate approach to be aplied in cases with nodule diameter [?]20 mm. Performing local imaging in patients with a nodule diameter of [?]20 $\mathrm{mm}$ could not only reduce radiation exposure but also save radiopharmaceuticals used in PET/CT imaging. Keywords: lung cancer, solitary pulmonary nodule, PET/CT, fluorodeoxyglucos
\end{abstract}

\section{Hosted file}

PETCT imaging Lung Cancer Article by QA 16072021.docx available at https://authorea.com/ users/429011/articles/532768-significance-of-local-f18-fdg-pet-ct-imaging-in-lung-cancer 